\title{
ORAL LICHEN PLANUS: A DISEASE OR A SPECTRUM OF TISSUE REACTIONS? TYPES, CAUSES, DIAGNOSTIC ALGORHYTHMS, PROGNOSIS, MANAGEMENT STRATEGIES
}

Marco Carrozzo, ${ }^{1}$ Stephen Porter, ${ }^{2}$ Valeria Mercadante, ${ }^{2}$ Stefano Fedele ${ }^{2,3}$

${ }^{1}$ Prof. Marco Carrozzo, Professor of Oral Medicine. Centre for Oral Health Research, Oral Medicine Department, Newcastle University, Framlington Place, NE2 4BW, Newcastle upon Tyne UK. Telephone: +4401912086797; Fax: +441912086137

2 Prof Stephen Porter, Director and Professor of Oral Medicine. UCL Eastman Dental Institute, University College London, 256 Gray's Inn Road, London WC1X 8LD, UK ${ }^{2}$ Dr Valeria Mercadante, Clinical Research Associate. UCL Eastman Dental Institute, University College London, 256 Gray's Inn Road, London WC1X 8LD, UK

${ }^{3}$ Dr Stefano Fedele, Clinical Senior Lecturer and Honorary Consultant in Oral Medicine, UCL Eastman Dental Institute, University College London, 256 Gray’s Inn Road, London WC1X 8LD, UK, NIHR University College London Hospitals Biomedical Research Centre, Maple House, Suite A, 1st floor, 149 Tottenham Court Road, London W1T 7DN, UK;

Corresponding author:

Dr Stefano Fedele (s.fedele@ucl.ac.uk) 


\section{Abstract}

Oral lichen planus and lichenoid lesions (OLP/OLL) comprise a group of disorders of the oral mucosa that likely represent a common reaction pattern to one or more unknown antigens. The coexistence of hyperkeratotic striation/reticulation, varying degrees of mucosal inflammation from mild erythema to severe widespread ulceration and a band-like infiltrate of mononuclear inflammatory cells including activated $\mathrm{T}$ lymphocytes, macrophages and dendritic cells are considered suggestive of OLP/OLL. Several classification systems of OLP/OLL have been attempted, though none seem to be comprehensive. In this paper we present a classification of OLP/OLL that includes oral lichen planus, oral lichenoid contact lesions, oral lichenoid drug reactions, oral lichenoid lesions of graft versus host disease, discoid lupus erythematosus, and systemic lupus erythematosus, lichen planus-like variant of paraneoplastic pemphigus/paraneoplastic autoimmune multi-organ syndrome, chronic ulcerative stomatitis, lichen planus pemphigoides, solitary fixed drug eruptions and lichen sclerosus. We present the clinical and diagnostic aspects of OLP/OLL and discuss related treatment options. 


\section{Introduction}

Oral lichen planus and lichenoid lesions (OLP/OLL) comprise a group of disorders of the oral mucosa that likely represent a common reaction pattern in response to extrinsic antigens, altered self-antigens or super antigens (89). Historically, there have been unresolved debates and controversies around the OLP/OLL terminology. The latter term has been frequently used to refer to oral lesions that have clinical and histopathological features similar to OLP but no risk of malignant transformation or to indicate an uncertain diagnosis of OLP. However, definitive clinical and histological diagnostic criteria able to distinguish OLP from OLL are still lacking (89). Furthermore, there remains no consensus regarding the possible different clinical behaviour of the disorders in the OLP/OLL group with respect to cancer development. In Dermatology, the concept of "lichenoid tissue reaction/interface dermatitis" (LTR/IFD) was introduced a long time ago to define a number of distinct inflammatory cutaneous diseases sharing common histopathological features including liquefactive/vacuolar changes of the basal keratinocytes and a sub-epithelial band-like array of mononuclear inflammatory cells including activated T lymphocytes, macrophages and dendritic cells $(89,156)$. During the 2006 World Workshop in Oral Medicine IV, it was proposed to classify the OLP/OLL group in four distinct disorders including OLP, oral lichenoid drug reactions (OLDR) caused by systemic drug exposure, oral lichenoid contact lesions (OLCL) triggered by local hypersensitive reaction to dental materials and oral lichenoid lesions of graft-versus-host disease (GVHD) (2). Although a step forward, this classification failed to provide clear and reliable clinical and histological criteria to properly differentiate these three types of OLL from OLP. In addition, several other disease entities characterised by clinical and/or histological features of LTR/IFD were excluded from the classification. Other authors have proposed alternative classifications $(42,76,173)$. Overall, there remains no consensus on classification, diagnostic criteria, clinical behaviour and management of the OLP/OLL $(1,28,174)$.

In this review, we have attempted to (i) update the classification of OLP/OLL, (ii) suggest pragmatic diagnostic criteria and (iii) define a management strategy. 


\section{Classification}

Table 1 lists the main disorders displaying histological and/or clinical characteristics of this OLL/OLP group. Some of these disorders are apparently uncommon whereas others are poorly defined or may simply represent a misnomer.

\section{Oral Lichen Planus}

OLP is the prototype disorder of the group. Despite the lack of reliable epidemiological data, OLP is thought to be relatively common, affecting approximately $1-2 \%$ of the population (147). OLP lesions are chronic and rarely undergo spontaneous remission (28); they can cause significant pain and morbidity and most authors would agree that they can undergo malignant transformation (52). OLP most commonly affects middle-aged adults of both sexes, with a slight female predominance, and without any apparent racial predilection (48). The distinctive clinical features of OLP are represented by the presence of white papules that enlarge and coalesce to form a reticular, annular or plaque-like pattern, the so-called Wickham's striae (28). Erythema, erosion and ulceration can also occur, often in association with white striae (Figure 1). The most commonly affected sites are the buccal mucosa bilaterally, the borders and dorsum of the tongue and the gingiva, whereas the palate (either hard or soft), the lips and the floor of the mouth are less commonly affected. Reticular/papular lesions are rarely symptomatic and patients are often unaware of their presence, whereas erythematous and erosive/ulcerative lesions usually result in a varying degree of discomfort or pain. When erosive/ulcerative lesions are predominant, confusion with diseases such as pemphigus vulgaris, mucous membrane pemphigoid (MMP) and persistent erythema multiforme (EM) is common $(28,48,147)$. Long lasting OLP lesions can be predominantly plaque-like, particularly in smokers; in the absence of typical reticular/papular lesions, this can raise significant diagnostic difficulties with other diseases such as oral leukoplakia. It should also be mentioned that dyskeratosis congenita can sometimes present with lichenoid features (64), and therefore all putative paediatric OLP cases should be carefully investigated for nail dystrophies, abnormal reticulate skin pigmentation, and haematological abnormalities. Individuals with OLP 
can also have extra-oral manifestations of lichen planus. The most frequent extra-oral site in females is the genital mucosa, with lesions developing in approximately $20 \%$ of women with OLP (61). The association of concomitant lichenoid lesions/lichen planus on the vulva, vagina and gingiva has been termed "vulvo-vaginal-gingival syndrome". Conversely, cutaneous lesions develop in just approximately $15 \%$ of patients with OLP (48). OLP is suggested to represent a T-cell-mediated immunological response to an unknown antigenic change in the skin or oral mucosa in predisposed patients (89). A key, early event in OLP pathogenesis is the genetically enhanced increased production of $\mathrm{TH} 1$ cytokines, particularly interferongamma (IFN- $\gamma$ ) and tumour necrosis factor-alpha (TNF- $\alpha$ ). However, a recent study has suggested that Th2-mediated inflammation can also contribute to OLP pathogenesis and progression through and can be induced by myeloid dendritic cells (mDCs), which in turn are activated by Thymic stromal lymphopoietin (TSLP) secreted by epithelial cells (185). Cytokine polymorphisms seem also to influence whether lesions would develop just in the mouth (IFNY associated) or also on the skin (TNF- $\alpha$ associated) (26). A recent meta-analysis has confirmed the association between $-308 \mathrm{G} / \mathrm{A}$ polymorphism in TNF- $\alpha$ gene and OLP (84). Studies of T cell receptor-variable region genes have also highlighted that OLP is likely to be the common outcome of a limited combination of extrinsic antigens, altered self-antigens or super antigens (167). Three meta-analyses have confirmed that OLP is associated with hepatitis C virus (HCV) $(98,100,132)$, which could be also involved in disease pathogenesis (133). Although the malignant potential of OLP remains controversial, a number of small uncontrolled studies and three large retrospective controlled studies from Denmark, Sweden and Italy, using strict diagnostic criteria, have strongly suggested that OLP patients do carry a significantly higher risk of developing oral squamous cell carcinoma (OSCC) than the general population $(57,71,140)$. A recent systematic review has suggested an overall rate of transformation of up to $3.5 \%$ (52). The clinical manifestations alone, particularly when presenting in the 'classic' bilateral keratotic reticular or papular form, may sometimes allow diagnosis (28) (Figure 1). However, given the chronic course and pleomorphic clinical manifestations, the need for long-term treatment and monitoring, and the risk of malignant 
transformation, a confirmatory surgical biopsy appears to represent prudent clinical practice. Histopathological confirmation is also important before starting an active treatment, as a common cause of therapy failure is inappropriate diagnosis (28). Histopathological assessment of OLP can however be difficult (173), although the assessment of the presence of dysplasia or malignancy is usually straightforward. Direct immunofluorescence (DIF) testing may be of diagnostic help in patients presenting with predominantly erosive/ulcerative OLP, so as to exclude other autoimmune blistering/ulcerative diseases. DIF of OLP is usually negative or can show shaggy fibrinogen deposits at the epithelial basement membrane zone or the so-called cytoid bodies (Russell bodies) (67). Sometimes, further immunological testing such as salt-split-skin, indirect immunofluorescence, immunoblot/immunoprecipitation and ELISAs are needed in order to achieve a definitive diagnosis and differentiate OLP from other blistering disorders, especially MMP (17). However, these techniques are costly, timedemanding and not widely available (25).

\section{Oral Lichenoid Contact Lesions (OLCL)}

Oral lichenoid contact lesion (OLCL) is a term used to describe oral lesions that resemble OLP both clinically and histopathologically but are thought to be caused by a localised (contact) hypersensitivity reaction to dental restorative materials, mainly amalgam $(8,112)$. Dental amalgam alloy is composed of a mixture of approximately equal parts of liquid mercury and a powder consisting of silver ( $22-32 \%)$, tin $(\sim 14 \%)$, copper $(\sim 8 \%)$, and other trace metals, including zinc (81). OLCLs to amalgams are supposed to represent a delayed hypersensitivity reaction (Coombs and Gell classification: type IV) to low-level mercury exposure (112). However, an animal model has failed to definitively prove that amalgam fillings can cause OLCL (46). A more recent study using the same animal model (Brown-Norway Rats) but with different exposure modalities, suggests that non-toxic mercury can rather cause lupus-like oral mucosal lesions (149).

Patch tests are commonly used to identify patients with suspected hypersensitivity reactions but their usefulness in OLCL have shown conflicting results (167). Skin testing is preferable to 
mucosal testing due to a higher sensitivity and specificity and because allergen concentration on mucosa needs to be 5-12 times higher than skin, potentially exposing patients to the risk of a toxic reaction. In vitro lymphocyte proliferation has been employed as an adjunctive tool in the diagnosis of allergies to various drugs (124) and metals (12), with the aim of restimulating antigen-specific lymphocytes (memory cells) from peripheral blood. The assay has a variety of modifications and names, for example, LTT (lymphocyte transformation test), LST (lymphocyte stimulation test), LPT (lymphocyte proliferation test), or MELISA® (memory lymphocyte immunostimulation assay). However, this test seems of limited utility to OLCL (29). The clinical appearance of OLCL has been rarely described in details. It is thought that OLCLs are less symmetrical and more commonly unilateral than OLP but supporting evidence remains scarce. Similarly, the close proximity of the lesions with amalgam restorations is commonly but not invariably reported (Figure 2). According to the published pictures, OLCLs might lack the typical reticular appearance of OLP and be more commonly patch-like or atrophic. They are usually located on posterior buccal mucosae and borders of the tongue. Histopathology could aid diagnosis if it shows a mixed cell sub-epithelial infiltrate and a deeper diffuse distribution in lamina propria. However, OLCL are often undistinguishable from other OLLs and OLP on histopathology assessment. There is also insufficient evidence to support routine removal of all amalgam restorations in patients with OLP/OLCL (8), although some authors have reported an improvement in $90 \%$ of the lesions after amalgam replacement in individuals with positive patch tests and lichenoid lesions in close contact with amalgam fillings (167).

\section{Oral Lichenoid Drug Reactions (OLDR)}

OLDR are caused by or associated with exposure to certain medications (2). They are thought to be uncommon compared to cutaneous lichenoid drug reactions but reliable data are scarce and OLDR are likely to be under-reported. The list of drugs that can cause OLDR is vast and includes angiotensin-converting enzyme inhibitors (ACE), non-steroidal anti-inflammatory inhibitors (NSAIDs), oral hypoglycaemic drugs, penicillamine, gold, beta-blockers, 
methyldopa, quinidine and quinine (109), diuretics (in particular hydrochlorothiazide), antifungals (e.g. ketoconazole), anticonvulsants (e.g. carbamazepine), immunomodulatory drugs (e.g. gold salts and penicillamine), sulfasalazine, and lithium (188). Recently, tumour necrosis factor alpha (TNF- $\alpha$ ) inhibitors infliximab and adalimumab have been reported in association with OLDR (5). OLDR may occur at any time, even years after the start of a certain drug therapy (163), although in many cases there seems to be a relatively clear temporal association between the use of the suspected medication and the onset of the oral lesions (2). There is currently no specific test for OLDR. Clinical appearance is unclear particularly compared to other OLLs, though the unilateral location may aid diagnosis (91). Histopathologically OLDR can present a sub-epithelial inflammatory infiltrate containing conspicuous eosinophils and/or plasma cells, which is more diffuse and extends more deeply than OLP, or has a perivascular appearance (45). Notably, none of these characteristics has been consistently reported and other OLL may present similar histopathological features, such as discoid lupus erythematosus (DLE) (109). The most reliable method of diagnosing an OLDR is to notice resolution after the withdrawal of the putative drug and the reappearance when the same drug is reintroduced. However, this is both impractical and potentially detrimental for the patient as some reactions may take weeks or months to resolve and the medication could be life-saving (2).

Circulating basal cell cytoplasmic antibodies (BCCA) are known to appear in drug eruptions and they have been studied in OLDR [38], but outcomes remain unclear. Autologous and allogeneic immunofluorescence tests seeking for lichen planus specific antigen (LPSA) seem not to aid diagnosis of OLDR (108).

\section{Oral Lichenoid Lesions of Graft Versus Host Disease (OLL-GVHD)}

Graft versus host disease (GVHD) is a major complication in patients receiving hematopoietic cell transplant (74). GVHD can be classified in acute or chronic (cGVHD), depending on the time to onset from the transplant (threshold is of the order of 100 days); however, the latest $\mathrm{NIH}$ consensus criteria recommend that classification should be based on characteristic 
symptoms and signs rather than a rigid temporal definition (51). Both acute and chronic GVHD can involve the mouth but lichenoid lesions are more common in the latter (74). Oro-facial manifestations occur in up to $80 \%$ of patients with cGVHD (74) and include three separate disease patterns that can coexist: (i) oral lichenoid lesions (OLL-GVHD) including reticulation, ulcerations and mucosal atrophy, (ii) salivary gland dysfunction with hyposalivation and persistent dry mouth symptoms and oro-facial fibrosis with restricted mouth opening $(51,182)$. The mucosal lesions are very similar to those found in OLP (Figure 3), the salivary gland infiltrates mimic those found in Sjögren's syndrome, and the fibrosis and reduced mouth opening are similar to the orofacial manifestations of scleroderma, that is also classified as a LTR/IFD (74). Histologically OLL-GVHD can be very similar to OLP. The typical clinical features of lichenoid lesions together with the history of allogeneic bone marrow transplant are often sufficient for the diagnosis of OLL-GVHD. Histological confirmation of OLL-GVHD is indicated in the absence of signs and symptoms of other systems or organs involvement and in cases of atypical clinical presentation. It is also important to consider development of dysplasia or malignancy, especially in patients with long-standing chronic disease.

\section{Lichen planus-like variant of Paraneoplastic Pemphigus/Paraneoplastic autoimmune multi-organ syndrome}

Paraneoplastic pemphigus (PNP) is an autoimmune syndrome, first described in 1990 (3), characterized by the development of muco-cutaneous lesions in individuals with a neoplastic, often malignant, disease. Although affected patients often present with blisters and ulceration similar to those of pemphigus vulgaris (hence the term PNP), the disorder can present a spectrum of clinical and histopathological manifestations that have been classified into 5 variants: 1) pemphigus-like, 2) pemphigoid-like, 3) erythema multiforme-like, 4) graft-vs-host disease-like, and 5) lichen planus-like. More recently, due to increasing evidence of the involvement of internal organs as one of the potential manifestations of the disease, the term "paraneoplastic autoimmune multiorgan syndrome" (PAMS) was introduced (119). Lichen planus-like variant of PNP/PAMS is frequently associated with Castleman's disease, which is 
a rare non-clonal neoplasm of lymphatic origin, also known as giant lymph node hyperplasia or benign giant cell lymphoma (122). Castleman's disease most commonly develops in lymphatic areas in the retroperitoneal spaces or in the chest and there is evidence that lesions may be present for very long periods of time before PNP/PAMS develops. The most common histological variant of Castleman's disease associated with PNP/PMAS is the hyaline vascular type (122).

PNP/PAMS is characterized by the presence of autoantibodies against multiple antigens, particularly the plakin family of proteins, which are part of the intracellular plaque of the desmosomes and/or hemidesmosomes. These include the $210 \mathrm{kDa}$ envoplakin (EP), the 190 kDa periplakin (PP), the $230 \mathrm{kDa}$ bullous pemphigoid antigen BP230, the 250 and $210 \mathrm{kDa}$ desmoplakins I and II (DSPI and DSPII), and the $500 \mathrm{kDa}$ plectin. Other antigens include the desmogleins (Dsg) 1 and 3, plakophilin 3, desmocollins 1-3 and the previously described 170 $\mathrm{kDa}$ autoantigen recently identified as the protease inhibitor alpha-2-macroglobulin-like-1 (A2ML1) (146). There seems to be an association with $\mathrm{HLA}^{-C w^{*} 14}$ and in $\mathrm{DRB} 1{ }^{*} 03$ in Chinese and French patients, respectively $(68,97)$, which is yet to be confirmed in other populations. In case of any recent or suspicious history of a neoplasm in patients developing oral or mucocutaneous lichenoid lesions a diagnosis of PNP/PAMS should be considered. Clinically, these patients have severe mucocutaneous lesions and can develop respiratory failure. They are typically refractory to standard treatment. Oral and skin manifestations are usually pleomorphic and can show a confusing and overlapping array of lesions (Figure 4). Histopathology is normally not of great aid. Routine immunologic tests such as direct and indirect immunofluorescence (IIF) can be either negative or controversial showing features of more than one disease entity. IIF analysis of PNP/PAMS sera demonstrates the presence of anti-epidermal antibodies that recognize both the epithelial cell surface of keratinocytes, typically seen in pemphigus vulgaris, and the basement membrane zone, seen in pemphigoid. The use of special substrates such as rat bladder epithelium that does not contain Dsg1 and 3 but does contain DSP, EP and PP greatly increases sensitivity (75-86\%) and specificity (8398\%) $(68,97)$. Several commercially available ELISAs are able to detect reactivity against 
some PNP antigens. In particular, an ELISA based on the N-terminal domain of EP is able to detect reactivity of $80.6 \%$ PNP patient sera (135). Immunoblotting can show a distinctive profile of antibodies directed toward the plakin family that include EP, PP, DSP, BPAG1, and plectin. However, the gold standard for diagnosis is still represented by immunoprecipitation (IP) of keratinocyte extracts. Historically, the first technique used to identify PNP autoantibodies was IP using radioactively labelled keratinocyte extracts (3). The sensitivity of this technique is superior to immunoblotting, IIF on rat bladder, and EP-ELISA. In addition, IP is able to identify anti-A2ML1 reactivity that is not detected by IB with PNP sera (146). However, because of the use of radioactive material, this technique is not widely available. Recently, non-radioactive IP has been introduced and it seems to have similar diagnostic performance (134).

\section{Lichenoid lesions of Discoid Lupus Erythematosus}

The term lupus erythematosus (LE) refers to a group of connective tissue disorders comprising at least three major disease subsets: 1) Systemic lupus erythematosus (SLE); 2) Subacute cutaneous LE (SCLE) and 3) Discoid lupus erythematosus (DLE). SLE and DLE can give rise to oral lichenoid lesions, which may appear similar if not identical to those of OLP. Immunofluorescent studies may be occasionally useful to distinguish oral lesions of LE from OLP (121) but they cannot always distinguish between the two disorders (117). The presence of mixed clinical and histopathological features of LE and LP, has been referred to as lupus erythematosus/ lichen planus overlap syndrome (LE/LP overlap syndrome) (117).

DLE is the common form of chronic cutaneous LE and can be separated into two groups: localized and generalized. The widespread disease is more frequently associated with abnormalities detected in laboratory tests (125). DLE has been associated with HLA region genes and non-MHC loci (see Table1) but the evidence is weaker than in $\operatorname{SLE}(79,80,118)$.

The disease may be confined to the skin, especially on sun-exposed areas, such as face, ears and scalp, but there may be also mucosal involvement which is usually limited to the oral and anogenital mucosae $(18,82,113,141,166,172,179,181)$. Up to $28 \%$ of patients with DLE are 
susceptible to developing SLE (35). Oral lichenoid lesions occur in 15-20\% of DLE cases but the prevalence of DLE limited to the oral mucosa is unknown and rarely studied. The buccal mucosa, the vermilion, the gingiva and palate are usually affected. Typical oral lesions are characterised by central atrophic areas or shallow erosions, radiating white striae at margins, characteristically far less sharply defined than in OLP. They are often unilateral, and may be on the hard and soft palate, and outer aspect of the lips which OLP usually spares. They can be the sole manifestation of the disease. Lip lesions can tend to spread from the vermilion to the surrounding lip skin, obscuring the limits of the vermilion but this is not a constant feature (120). Squamous cell carcinoma may rarely arise in longstanding lesions of oral DLE (99). Patients with DLE rarely fulfil 4 or more of the criteria used to classify SLE (161). Serologic abnormalities are particularly uncommon in localized disease. The predominant autoantibody in DLE patients remains unknown and only low-titre anti-Ro (60 kDa) antibodies have been found in DLE patients (36). Histopathology can sometimes be of help but frequently is equivocal or not specific, particularly in distinguishing DLE from OLP (168). On direct immunofluorescence testing granular deposition of immunoglobulin and/or complement can be seen at the dermo-epidermal junction, the so called lupus band test (LBT): this is characteristic but not pathognomonic of either DLE or SLE. The LBT is neither sensitive nor specific and has mostly been replaced by advances in serologic testing (73).

\section{Lichenoid Lesions of Systemic Lupus Erythematosus}

SLE is regarded as a prototypic systemic autoimmune disease, which can affect multiple organs and systems. Genome-wide association studies and mapping of candidate regions have allowed a better understanding of the genetic basis of SLE (65). A meta-analysis found the most consistent HLA association with HLA-DR3 and DR2 in European populations (50), whereas a genome-wide association study (GWAS) revealed a greater association with MSH5 gene, which is in the class III region (66). Table 1 lists the candidate gene associations confirmed by GWAS. Given the large number of SLE susceptibility loci known, it seems that the genetic risk of SLE is derived from variations in several genes, each being of modest effect 
size (65). SLE most often manifests as a mixture of constitutional symptoms, with skin, musculoskeletal, and hematologic involvement. However, some patients present with predominantly hematologic, renal, or neuropsychiatric manifestations (58). Cutaneous manifestations of SLE are present in $85 \%$ of patients during the course of the disease. The most typical skin lesion of LE is erythema over the malar eminences of the face and bridge of the nose (the so called butterfly rash). Oral lesions appear in up to $40 \%$ of cases of SLE and can rarely be the presenting sign of the disease $(85,86)$. Oral manifestations of SLE can be similar to DLE: oral lichenoid lesions with atrophy, erosion and hyperkeratotic reticulation and striation (Figure 5). Histopathological and immunofluorescence features have been discussed above in the DLE section. Otherwise unspecific oral ulcerations can also be seen and they are an American College of Rheumatologists (ACR) criterion for SLE diagnosis (111). According to the ACR, the diagnosis of SLE requires the presence of four or more of 11 criteria, serially or simultaneously, during any period of observation (58). Diagnosis of SLE is also challenging because typical symptoms and signs could take long time to establish. The diagnosis should be confirmed by the pattern of autoantibodies, particularly anti-nuclear antibodies (ANA). Further to double-stranded DNA autoantibodies other autoantibodies are commonly detected in SLE. Some SLE autoantibodies are pathogenic and others are protective and some appear to be neutral, indifferent, and/or have roles that may not be directly traced to pathogenesis or protection (55).

\section{Chronic Ulcerative Stomatitis}

In 1990 Jaremko et al. (78) described a disease, which they named chronic ulcerative stomatitis (CUS), characterized by chronic oral ulcerations that occasionally can involve the skin $(23,38,43,53,75,152,153,155,183)$. The clinical appearance of oral lesions of CUS is reminiscent of OLP and specific features able to differentiate CUS from OLP are virtually nonexistant. Some authors report that CUS should be considered in patients unresponsive to glucocorticosteroid therapy (53). No more than 40 cases have been reported since the original description and it is still unclear if this disease exists as a separate entity from OLP. The 
histologic features are non-specific, with a chronic inflammatory infiltrate, often appearing similar to OLP. Diagnosis of CUS requires immunofluorescence (IF) microscopic examination (138). Direct IF reveals the presence of IgG antibodies bound to of keratinocytes nuclei of the basal and lower one-third cell layers, with a unique stratified epithelial specific-antinuclear antibody (SES-ANA) pattern (78). However, other disorders such as SLE, scleroderma and CREST (Calcinosis, Raynaud's phenomenon, Oesophageal involvement, Sclerodactyly and Telangectasia) syndrome, and mixed connective tissue disease (MCTD), may demonstrate a similar ANA pattern (152). CUS patients also have circulating antibodies which exhibit the SES-ANA pattern on indirect IF (IIF) using an oesophagus substrate (78). Circulating IgG in SLE, CREST, and MCTD patients $(38,127,175)$ are usually detected using human neoplastic HEp-2 cells or rodent kidney cells as substrates but they are not suitable for IIF of suspected CUS cases. SLE, scleroderma and MCTD may also be positive for ANA on oesophagus substrates but the pattern is different because the antibodies should be distributed through the superficial epithelial layers (152). Immunoblot studies led to the recognition of a $70-k D a$ keratinocyte protein in some CUS cases $(16,24,128)$. Further studies identified a nuclear protein normally present in basal and parabasal cells of stratified squamous epithelia called deltaNp63alpha $(\Delta \mathrm{np63 \alpha})$, which is thought to be the putative specific CUS antigen (93). $\Delta \mathrm{np63 \alpha}$ is a member of a family of nuclear transcription factors, including $\mathrm{p} 63, \mathrm{p} 73$, and the p53 tumor suppressor gene, which share considerable sequence homology (34). It is still debated if $\Delta$ np63a is specific of CUS as some Authors reported that OLP patients could have circulating autoantibodies against this protein (128). Two novel non-commercial ELISA systems have been developed to detect antibodies against $\Delta$ np63a $(47,154)$.

\section{Lichen Planus Pemphigoides}

Lichen planus pemphigoides (LPP) is a rare clinical variant of bullous pemphigoid (BP), which is characterized by clinical and histological features of both LP and BP. This immuno-bullous disorder usually occurs on skin and occasionally involves the oral mucosa $(154,180,189)$. Less than 80 cases have been reported so far and about $40 \%$ reported oral lesions similar to those 
of OLP (189). Only 3 cases of LPP limited to the oral mucosa have been published $(114,154)$, though similar clinical appearance and immunological testing led to a MMP diagnosis in at least another published case (92). LLP seems to have a similar demographic to OLP, with a slight female predominance and mean age at diagnosis of 54 years (189). LPP has been associated with a wide variety of conditions including malignancies such as lymphoma, haemangiopericytoma, and colon cancer, and other conditions and therapies such as viral hepatitis, phototherapy (UVA, UVB/psoralen-UVA), and therapy with simvastatin, furosemide, ramipril, captopril, cinnarizine, paracetamol and ibuprofen $(63,105,114,123,158)$. Clinically, LPP is characterized by formation of blisters or tense bullae prior to, during, or after a papular eruption of cutaneous LP. The bullae arise on both normal and LP affected skin $(39,154)$. Clinical features of oral involvement in LPP are lichenoid striation, erythematous and ulcerative lesions involving gingiva, buccal mucosa but also the palate (Figure 6). Classic diagnosis of LPP is made by clinical, histopathologic and immunologic features that suggest the concurrence of both LP and BP $(39,154,160)$. Histopathology shows features of orthokeratosis, hypergranulosis, irregular acanthosis, hydropic degeneration of basal keratinocytes with citoid body formation and subepidermal clefting (at the level of the lamina lucida). The dermal inflammatory infiltrate is inconstant and may be cell-rich or cell-poor, lichenoid or perivascular; in addition, eosinophilic spongiosis may also be a feature $(144,154,187)$. The sub-epidermal blister shows linear deposition of $\lg G$ and/or C3 along the dermal-epidermal junction (DEJ) upon DIF. In addition, more than $50 \%$ of LPP cases have circulating IgG anti-BMZ antibodies that are deposited on the epidermal side of $1.0 \mathrm{M}$ sodium chloride split skin indirect immunofluorescence. By immunoblot, sera of LPP patients react against BP180, a component of the hemidesmosome involved in the dermo-epidermal anchoring complex. In particular, autoantibodies bind to the C-terminal portion of NC16A, a non-collagenous region of BP180 recognized by the vast majority of BP and MMP patients $(10,190)$. In this context, the commercially available ELISA based on NC16A can contribute to the diagnosis. 


\section{Mixed Group}

Lichenoid lesions on the inner side of the lip, possibly initiated by microbial plaque accumulation on the buccal surfaces of the anterior teeth, have been reported as a possible new disease entity $(9,107)$. All subjects presented with a localized erythematous patch on the labial mucosa of the upper lip and microscopically the lesions were characterized by the presence of lichenoid inflammation with concomitant granulomatous inflammation.

Solitary fixed drug eruptions on the lip have been rarely reported. They are characterized by a peculiar sudden onset of solitary, or occasionally multiple, well demarcated erythematous lesions on the mucous membranes which may or may not become ulcerated. The histopathology shows lichenoid interface dermatitis that includes plasma cells and tends to surround small vessels (130). The diagnostic hallmark is the reappearance of the lesion precisely over the previously affected site when the offending agent is reused.

Lichen sclerosus (LC) is clinically characterized by the development of well-delimited hyperkeratotic lesions to the skin and genitals, and very rarely to the oral mucosa, followed by fibrosis/sclerosis $(7,83)$. It can mimic other disorders causing hyperkeratotic patches including OLP. Histopathology of LC shows epithelial atrophy, local hydropic degeneration of the basal cells, loss of the epithelial crests, and homogenization of the underlying connective tissue with a reduction in elastic fibre presence, hyalinization and connective tissue sclerosis. Lichenoid lymphocytic infiltrate is often present but does not show a distinct band of lymphocytes at the epithelial-connective tissue junction as in OLP and other lichenoid lesions (7).

\section{Differential Diagnosis of OLL}

Occasionally the diagnosis of a specific OLL may be made on visual inspection without any further test but in most instances other investigations are warranted (Figure 7). OLL often present overlapping clinical and histopathological features and diagnosis is frequently challenging. A complete history and clinical assessment by a multidisciplinary group of specialists may be required to investigate oral, skin, nail, scalp, genital, oesophageal, laryngeal and conjunctival involvement. 
The clinical features alone, particularly when presenting in the "classic" hyperkeratotic reticular bilateral form, would often support the exclusion of other oral keratotic disease such as leukoplakia, frictional keratosis and proliferative verrucous leucoplakia (156). The latter is particularly difficult to address as available reports suggest that it can show histological "lichenoid" features. Biopsy would be prudent clinical practice in most, if not all, patients. Histopathology, however, can be subjective and nonspecific (28); also it is unlikely to allow differentiation between OLL. Further investigations such as direct and salt-split skin indirect immunofluorescence and ELISA tests may be needed when a bullous disorders or LPP and CUS are suspected. In cases of recalcitrant and atypical muco-cutaneous manifestations, further investigations are warranted including a PET-scan for total body cancer screening if PNP/PAMS is suspected. Immunoblotting, IP and ELISAs may also assist diagnosis (Figure 7).

When medical history, clinical features and immunological findings (for example positive ANA test) suggest SLE, testing fro anti-DNA antibodies as well as and other autoantibodies including Anti-Sm, anti-RNP, anti-Ro/SSA and La/SSB, anti-antiphospholipid and anticardiolipin should be considered (Table 1) (Figure 7) (55). For some OLL such as DLE, OLDR and OLCL, reliable diagnostic tests are not available and further research is warranted.

\section{Management of OLP/OLL}

Some OLL such as OLP, OLCL, OLDR, DLE and CUS are more amenable to topical therapy than PNP/PAMS, SLE and LPP, which usually require systemic medications and multidisciplinary management. This chapter will focus upon topical therapy of OLP/OLL.

In individuals with potential OLDR, the causing medication should be discontinued where possible. This is often difficult because the drug is usually important to the patient's health and effective alternative drugs may not be available. Moreover, the lesions may persist for several months following withdrawal of the medication (109). Patients suspected to have OLCL may benefit from targeted amalgam replacement, although it is possible that simple polishing of the restorations and improvement of the patient's oral hygiene may minimize plaque 
accumulation and frictional trauma to the mucosa and therefore results in an improvement of the OLCL. Patients obviously should be counselled on benefits and risks of amalgam removal. Also, the cyclic nature of the disease characterized by periods of spontaneous remission and exacerbation, the limited evidence supporting amalgam replacement, and the unpredictability of the amalgam removal procedure should be described. Risks should be fully disclosed: these include potential iatrogenic dental damage, the possibility of the worsening of the lesions immediately after amalgam replacement (especially if a rubber dam is not used), shorter life span of some alternative materials, and possible additional allergic reactions involving any of the newly placed restoration materials (8).

The main aim of any therapy of OLP/OLL is symptomatic control $(28,164)$. Usually, patients with reticular and other asymptomatic lesions do not require active treatment. The elimination of potential precipitating or provoking factors is an important initial step in the management of symptomatic OLP/OLL. Precipitating factors and irritants (sharp or fractured teeth, poorly fitting dentures, alcohol and tobacco consumption) should be identified and avoided or eliminated where possible (73). Good oral hygiene along with the use of chlorhexidine mouth rinse should also be advocated, as plaque reduction may have beneficial effects on the lesions (70).

As many cases of OLP/OLL are chronic, the patient's medical history, psychological state, and treatment compliance as well as possible drug interaction must be considered when evaluating the cost effectiveness of any treatment modality (27).

Although a permanent cure is not available, various treatment regimens (Table 2) have been introduced to reduce and control painful symptoms of OLP/OLL. Curiously, several suggested treatment modalities are also suspected to induce lichenoid lesions (Table 2). Topical agents are usually the first line of therapy as they have few adverse side effects. However, systemic agents may be required if lesions are widespread and involve the skin or other mucosae, or if there is recalcitrant disease. The medications that are commonly used for OLP/OLL are immunosuppressive and few were developed specifically for oral disease. As a result, there is a lack of adequate studies determining their efficacy (164). Moreover, several aspects of the 
therapy such as optimal dose, duration of treatment, safety, and true efficacy remain largely unknown (148). Patients should be warned about the off-label use of the medications used to treat OLP/OLL.

\section{Topical corticosteroids}

Topical corticosteroids (TCS) are universally recognized as first-line treatment of symptomatic OLP/OLL. However it remains unclear which steroid potency, formulation, concentration or dosage regimen represents "standard of care" (164).

Commonly, ointments and suspensions are preferred whereas creams can have a bitter taste and do not melt well with adhesive pastes whereas gels almost invariably contain alcohol and sting. Sprays, normally used for nasal allergy and asthma, can be also used intra-orally.

A reduction in painful symptoms with mid-potency corticosteroids, such as triamcinolone acetonide $0.1 \%$ and betamethasone, potent fluorinated corticosteroids such as fluocinolone acetonide $0.1 \%$ and fluocinonide $0.05 \%$, and super potent halogenated corticosteroids, such as clobetasol propionate $0.05 \%$, have been reported in $30-100 \%$ of treated patients $(15,20,21,103,139,165,177)$. The adherence to the oral mucosa for a sufficient length of time can be enhanced using adhesive pastes, such as sodium carboxymethyl cellulose (Orabase $\AA$ ) and hydroxyethyl cellulose, or special drug delivery systems, such as lipid-loaded microspheres $(19,21,103,116)$. latrogenic Cushing's syndrome has been rarely reported using TCS $(44,59,94)$ whereas acute pseudo-membranous candidiasis is the most common adverse side effect. This can be prevented with the use of antifungals (miconazole gel) or chlorhexidine mouthwashes $(21,101)$. When lesions of OLP/OLL are limited to the gingivae topical steroids may be best delivered using custom made trays (60).

\section{Other topical agents}

Other topical immunosuppressants or immunomodulatory agents such as calcineurin inhibitors ( $\mathrm{TCl}$ ) (cyclosporine, tacrolimus, or pimecrolimus) or retinoids have been reported to be beneficial for symptomatic OLP/OLL, especially if the lesions are recalcitrant to 
corticosteroids. Cyclosporine has been used as a mouthrinse (50-1500 mg/day) (127) or in adhesive bases $(26-48 \mathrm{mg} /$ day) $(40,49,77,96,151,178)$ but is expensive, not always effective, and less beneficial than topical clobetasol in inducing clinical improvement (40). Tacrolimus is 10-100 times as potent as cyclosporine and has greater percutaneous absorption. Several uncontrolled, not randomised studies have documented the efficacy and safety of this agent in the management of recalcitrant erosive OLL at concentrations ranging from $0.03 \%$ up to $0.1 \%(41,69,87,95,115,126,142)$. Burning on application is a common side-effect and is observed in $<20 \%$ of patients. Circulating therapeutic levels of tacrolimus can be demonstrated after topical application and occasionally they can cause systemic adverse events (41). Pimecrolimus is the newest calcineurin inhibitor used in OLP/OLL treatment. Its immunosuppressive potency is thought to be weaker than cyclosporine and tacrolimus and it has lower permeation through the skin than topical steroids or topical tacrolimus. Nevertheless, a recent RCT comparing pimecrolimus $1 \%$ versus tacrolimus $0.1 \%$ in adhesive ointment in the management of symptomatic OLP/OLL did not show any difference in clinical efficacy (4). Although four small placebo-controlled randomised trials suggested that $1 \%$ pimecrolimus cream can be an effective and well-tolerated treatment for erosive OLP/OLL $(110,129,159,176)$, a very recent meta-analysis $(129,159,176)$ reported that in fact there is no robust evidence that pimecrolimus is more effective than placebo (164).

The US Food and Drugs Administration issued a "Black Box" warning regarding the use of tacrolimus and pimecrolimus because of a possible increased risk of malignancy development (squamous cell carcinoma and lymphoma) in patients using topical tacrolimus/pimecrolimus for cutaneous diseases. The decision has been heavily criticized in the medical community as the concern stemmed from case reports and animal data (150). A recent 'deductive metaanalysis' found no evidence of increased risk of skin cancer associated with the use of TCls (162). The issue remains controversial, as two separate papers reported development of oral SCC in two patients with OLP/OLL and history of topical tacrolimus $0.1 \%$ therapy $(11,106)$. Topical rapamycin (Sirolimus), which inhibits the response to interleukin-2 (IL-2) and blocks activation of T- and B-cells, has been recently suggested to represent an effective alternative 
therapy in refractory erosive OLP (157). Notably, rapamycin has both immunosuppressive and tumour inhibitor properties, and might theoretically control painful symptoms and at the same time lessen the risk of cancer development in OLP/OLL patients.

Topical retinoids such as tretinoin, isotretinoin, fenretinide and tezarotene are generally less effective than topical corticosteroids and more likely to cause adverse side effects $(13,14,131,145,170)$.

\section{Systemic therapy}

Systemic corticosteroids are recommended for patients with severe painful OLP/OLL who have failed to respond to topical therapy or have widespread OLP/OLL involving skin, genitals, oesophagus, or scalp (22). Prednisolone at a starting dosage of 40 to $80 \mathrm{mg}$ daily for 1-4 weeks is usually sufficient to achieve a notable response, often followed by slow reduction in dosage. However recurrences are common and therefore systemic corticosteroids do not represent a sensible therapeutic option in chronic OLP/OLL (102) due to their toxicity profile associated with long-term therapy. Corticosteroid-sparing agents and other immunosuppressants including azathioprine and mycophenolate mofetil are usually required for long-term therapy $(32,33,54,136,169,186)$, though there has been little robust evaluation of their efficacy in the OLP/OLL population. Hydroxychloroquine sulphate is considered the first-line systemic therapy for severe DLE (82) but it could be also effective for CUS. Also, very recently, biologic agents including Basiliximab, Etanercept, Efalizumab and Alefacept have been proposed for treatment of OLP/OLL (Table 2), especially for patients with severe manifestations or those who have failed traditional first- and second-line therapy such as topical corticosteroids/topical calcineurin inhibitors. Non-pharmacological modalities such as phototherapy (62), surgery (6) and laser treatment (with carbon dioxide and low-dose excimer 308 -nm laser) $(72,90,171)$ have been suggested but their effectiveness is yet to be proven. Of note, surgical intervention has been reported to worsen lesions of OLP/OLL (88).

\section{Novel treatments}


Topical aloe vera (AV) $(37,104,137,143)$ and oral curcuminoids (OC) $(30,31)$ have been suggested to represent promising therapeutic options for OLP/OLL. However, different AV formulations have been published so far and the amount of active product can vary greatly depending on the age of the plant, the growing and harvesting conditions, the parts of the plant, and the extraction methods used. Further, OC can cause adverse side effects in up to $40 \%$ of the patients, including liver dysfunction.

Amlexanox (56) and topical thalidomide (184) have also been investigated and were reported to be effective in controlling painful symptoms of OLP/OLL in comparison to weak topical corticosteroids, which are no longer commonly used for OLP/OLL management.

\section{Conclusions}

OLP/OLL represent a heterogeneous group of inflammatory disorders that are characterised by similar clinical manifestations and histopathological features. They probably share a common reaction pattern to one or more antigens, however the exact pathogenic mechanisms and the nature of antigenic triggers remain unknown. Oral manifestations typically include "lichenoid" hyperkeratotic striation/reticulation and/or a variable degree of erythema, blistering, erosion and ulceration, which are seen in oral lichen planus, oral lichenoid contact lesions, oral lichenoid drug reactions, oral lichenoid lesions of graft versus host disease, discoid lupus erythematosus, and systemic lupus erythematosus, lichen planus-like variant of paraneoplastic pemphigus/paraneoplastic autoimmune multi-organ syndrome, chronic ulcerative stomatitis, lichen planus pemphigoides, solitary fixed drug eruptions and oral lichen sclerosus. Histologically OLP/OLL are characterised by a "lichenoid" sub-epithelial inflammatory infiltrate of lymphocytes. With the exception of oral lichen planus and sclerosus, oral lichenoid contact lesions, oral lichenoid drug reactions, and chronic ulcerative stomatitis, affected patients often present a variety of extra-oral systemic manifestations that require assessment and management. Oral painful lesions of OLP/OLL are commonly managed with topical corticosteroids and immunosuppressants, although severe recalcitrant disease and extra-oral manifestations typically require systemic immunosuppression. Some of the 
disorders in the OLP/OLL group are associated with an increased risk of oral cancer development and should be carefully and regularly monitored. 


\section{References}

1. Aguirre Urizar JM. Letter to the editor: Oral lichenoid disease. A new classification proposal. Med Oral Patol Oral Cirugia Bucal 2008: 13: 224.

2. Al-Hashimi I, Schifter M, Lockhart PB, Wray D, Brennan M, Migliorati CA, Axéll T, Bruce AJ, Carpenter W, Eisenberg E, Epstein JB, Holmstrup P, Jontell M, Lozada-Nur F, Nair R, Silverman $B$, Thongprasom K, Thornhill M, Warnakulasuriya S, van der Waal I. Oral lichen planus and oral lichenoid lesions: diagnostic and therapeutic considerations. Oral Surg Oral Med Oral Pathol Oral Radiol Endodontology 2007: 103: S25.e1-S25.e12.

3. Anhalt GJ, Kim S, Stanley JR, Korman NJ, Jabs DA, Kory M, Izumi H, Ratrie III H, Mutasim D, Ariss-Abdo L, Labib RS. The new england journal of medicine dec. 20, 1990 paraneoplastic pemphigus: An autoimmune mucocutaneous disease associated with neoplasia. $N$ Engl J Med 1990: 323: 1729-1735.

4. Arduino PG, Carbone M, Della Ferrera F, Elia A, Conrotto D, Gambino A, Comba A, Calogiuri PL, Broccoletti R. Pimecrolimus vs. tacrolimus for the topical treatment of unresponsive oral erosive lichen planus: A 8 week randomized double-blind controlled study. J Eur Acad Dermatol Venereol 2014: 28: 475-482.

5. Asarch A, Gottlieb AB, Lee J, Masterpol KS, Scheinman PL, Stadecker MJ, Massarotti EM, Bush ML. Lichen planus-like eruptions: An emerging side effect of tumor necrosis factor- $\alpha$ antagonists. J Am Acad Dermatol 2009: 61: 104-111.

6. Axéll T, Henriksen BM. Treatment of gingival lichen with free palatal grafts. J Oral Pathol Med 2007: 36: 105-109.

7. Azevedo RS, Romañach MJ, de Almeida OP, Mosqueda-Taylor A, Vega-Memije ME, CarlosBregni R, Contreras-Vidaurre E, López-Jornet $P$, Saura-Inglés A, Jorge J. Lichen sclerosus of the oral mucosa: clinicopathological features of six cases. Int J Oral Maxillofac Surg 2009: 38: 855860.

8. Baccaglini L, Thongprasom K, Carrozzo M, Bigby M. Urban legends series: Lichen planus. Oral Dis 2013: 19: 128-143.

9. Bäckman K, Jontell M. Microbial-associated oral lichenoid reactions. Oral Dis 2007: 13: 402406.

10. Barnadas MA, Roé E, Dalmau J, Alomar A, Martínez L, Gelpí C. Lichen planus pemphigoides: Detection of anti-BP 180 antibodies by ELISA and immunoblotting tests. J Eur Acad Dermatol Venereol 2010: 24: 1360-1361.

11. Becker JC, Houben R, Vetter CS, Bröcker EB. The carcinogenic potential of tacrolimus ointment beyond immune suppression: A hypothesis creating case report. BMC Cancer 2006: 6. doi:10.1186/1471-2407-6-7

12. von Blomberg-van der Flier M, van der Burg CKH, Pos O, van de Plassche-Boers EM, Bruynzeel DP, Garotta G, Scheper RJ. In vitro studies in nickel allergy: Diagnostic value of a dual parameter analysis. J Invest Dermatol 1987: 88: 362-368. 
13. Boisnic S, Branchet MC, Pascal F, Ben Slama L, Rostin M, Szpirglas H. Topical tretinoin for treatment of oral lichen planus and oral leukoplakia: Clinical study. Ann Dermatol Venereol 1994: 121: 459-463.

14. Buajeeb W, Kraivaphan P, Pobrurksa C. Efficacy of topical retinoic acid compared with topical fluocinolone acetonide in the treatment of oral lichen planus. Oral Surg Oral Med Oral Pathol Oral Radiol Endod 1997: 83: 21-25.

15. Buajeeb W, Pobrurksa C, Kraivaphan P. Efficacy of fluocinolone acetonide gel in the treatment of oral lichen planus. Oral Surg Oral Med Oral Pathol Oral Radiol Endod 2000: 89: 42-45.

16. Cacciapuoti M, Di Marco E, Cozzani E, Zerega B, Cancedda FD, Parodi A. The antibody to the 70kd antigen in chronic ulcerative stomatitis and lichen planus [9]. J Am Acad Dermatol 2004: 50: 486.

17. Calabresi V, Carrozzo M, Cozzani E, Arduino P, Bertolusso G, Tirone F, Parodi A, Zambruno G, Di Zenzo G. Oral pemphigoid autoantibodies preferentially target BP180 ectodomain. Clin Immunol 2007: 122: 207-213.

18. Callen JP. Cutaneous lupus erythematosus: A personal approach to management. Australas J Dermatol 2006: 47: 13-27.

19. Campisi G, Giandalia G, De Caro V, Di Liberto C, Aricò P, Giannola LI. A new delivery system of clobetasol-17-propionate (lipid-loaded microspheres $0.025 \%$ ) compared with a conventional formulation (lipophilic ointment in a hydrophilic phase $0.025 \%$ ) in topical treatment of atrophic/erosive oral lichen planus. A Phase IV, randomized, observer-blinded, parallel group clinical trial. Br J Dermatol 2004: 150: 984-990.

20. Carbone M, Arduino PG, Carrozzo M, Caiazzo G, Broccoletti R, Conrotto D, Bezzo C, Gandolfo S. Topical clobetasol in the treatment of atrophic-erosive oral lichen planus: A randomized controlled trial to compare two preparations with different concentrations. J Oral Pathol Med 2009: 38: 227-233.

21. Carbone M, Conrotto D, Carrozzo M, Broccoletti R, Gandolfo S, Scully C. Topical corticosteroids in association with miconazole and chlorhexidine in the long-term management of atrophicerosive oral lichen planus: A placebo-controlled and comparative study between clobetasol and fluocinonide. Oral Dis 1999: 5: 44-49.

22. Carbone M, Goss E, Carrozzo M, Castellano S, Conrotto D, Broccoletti R, Gandolfo S. Systemic and topical corticosteroid treatment of oral lichen planus: A comparative study with long-term follow-up. J Oral Pathol Med 2003: 32: 323-329.

23. Carlson MW, Garlick JA, Solomon LW. Chronic ulcerative stomatitis: Evidence of autoimmune pathogenesis. Oral Surg Oral Med Oral Pathol Oral Radiol Endodontology 2011: 111: 742-748.

24. Carrizosa AM, Elorza FL, Camacho FM. Antinuclear antibodies in patients with lichen planus. Exp Dermatol 1997: 6: 54-56.

25. Carrozzo M. A reappraisal of diagnostic criteria for mucous membrane pemphigoid. J Oral Pathol Med 2009: 38: 160. 
26. Carrozzo M, De Capei MU, Dametto E, Fasano ME, Arduino P, Broccoletti R, Vezza D, Rendine S, Curtoni ES, Gandolfo S. Tumor Necrosis Factor- $\alpha$ and Interferon- $\gamma$ Polymorphisms Contribute to Susceptibility to Oral Lichen Planus. J Invest Dermatol 2004: 122: 87-94.

27. Carrozzo M, Gandolfo S. The management of oral lichen planus. Oral Dis 1999: 5: 196-205.

28. Carrozzo M, Thorpe R. Oral lichen planus: a review. Minerva Stomatol 2009: 58: 519-537.

29. Cederbrant K, Gunnarsson L-G, Hultman P, Norda R, Tibbling-Grahn L. In vitro lymphoprolif erative assays with $\mathrm{HgCl} 2$ cannot identify patients with systemic symptoms attributed to dental amalgam. J Dent Res 1999: 78: 1450-1458.

30. Chainani-Wu N, Madden E, Lozada-Nur F, Silverman Jr. S. High-dose curcuminoids are efficacious in the reduction in symptoms and signs of oral lichen planus. J Am Acad Dermatol 2012: 66: 752-760.

31. Chainani-Wu N, Silverman Jr. S, Reingold A, Bostrom A, Mc Culloch C, Lozada-Nur F, Weintraub J. A randomized, placebo-controlled, double-blind clinical trial of curcuminoids in oral lichen planus. Phytomedicine 2007: 14: 437-446.

32. Chang ALS, Badger J, Rehmus W, Kimball AB. Alefacept for erosive lichen planus: A case series. J Drugs Dermatol 2008: 7: 379-383.

33. Cheng A, Mann C. Oral erosive lichen planus treated with efalizumab. Arch Dermatol 2006: 142: 680-682.

34. Choi H-R, Batsakis JG, Zhan F, Sturgis E, Luna MA, El-Naggar AK. Differential expression of p53 gene family members p63 and p73 in head and neck squamous tumorigenesis. Hum Pathol 2002: 33: 158-164.

35. Chong BF, Song J, Olsen NJ. Determining risk factors for developing systemic lupus erythematosus in patients with discoid lupus erythematosus. Br J Dermatol 2012: 166: 29-35.

36. Chong BF, Tseng L-C, Lee T, Vasquez R, Li QZ, Zhang S, Karp DR, Olsen NJ, Mohan C. IgG and IgM autoantibody differences in discoid and systemic lupus patients. J Invest Dermatol 2012: 132: 2770-2779.

37. Choonhakarn C, Busaracome P, Sripanidkulchai B, Sarakarn P. The efficacy of aloe vera gel in the treatment of oral lichen planus: A randomized controlled trial. Br J Dermatol 2008: 158: 573-577.

38. Chorzelski TP, Olszewska M, Jarzabek-Chorzelska M, Jablonska S. Is chronic ulcerative stomatitis an entity? Clinical and immunological findings in 18 cases. Eur J Dermatol 1998: 8: 261-265.

39. Cohen DM, Ben-Amitai D, Feinmesser M, Zvulunov A. Childhood lichen planus pemphigoides: A case report and review of the literature. Pediatr Dermatol 2009: 26: 569-574.

40. Conrotto D, Carbone M, Carrozzo M, Arduino P, Broccoletti R, Pentenero M, Gandolfo S. Ciclosporin vs. clobetasol in the topical management of atrophic and erosive oral lichen planus: A double-blind, randomized controlled trial. Br J Dermatol 2006: 154: 139-145. 
41. Conrotto D, Carrozzo M, Ubertalli AV, Gandolfo S, Giaccone L, Boccadoro M, Benedetto B. Dramatic increase of tacrolimus plasma concentration during topical treatment for oral graftversus-host disease [3]. Transplantation 2006: 82: 1113-1115.

42. Cortés-Ramírez D-A, Gainza-Cirauqui M-L, Echebarria-Goikouria M-A, Aguirre-Urizar JM. Oral lichenoid disease as a premalignant condition: The controversies and the unknown. Med Oral Patol Oral Cirugia Bucal 2009: 14: E118-E122.

43. Cozzani E, Cacciapuoti M, Di Marco E, Zerega B, Cancedda FD, Parodi A. Patients with oral erosive and cutaneous lichen planus may have antibodies directed against the chronic ulcerative stomatitis protein antigen of 70-kDa. Acta Dermatovenerol Alp Pannonica Adriat 2008: 17: 120-124.

44. Decani S, Federighi V, Baruzzi E, Sardella A, Lodi G. latrogenic Cushing's syndrome and topical steroid therapy: Case series and review of the literature. J Dermatol Treat 2014: 25: 495-500.

45. Den Haute VV, Antoine JL, Lachapelle JM. Histopathological discriminant criteria between lichenoid drug eruption and idiopathic lichen planus: Retrospective study on selected samples. Dermatology 1989: 179: 10-13.

46. Dunsche A, Frank MP, Lüttges J, Açil Y, Brasch J, Christophers E, Springer ING. Lichenoid reactions of murine mucosa associated with amalgam. Br J Dermatol 2003: 148: 741-748.

47. Ebrahimi M, Nylander E, Bäcklund B, Wahlin Y-B, Coates PJ, Nylander K. The use of a novel ELISA method for detection of antibodies against p63 in sera from patients diagnosed with oral and/or genital and skin lichen planus. J Oral Pathol Med 2010: 39: 486-490.

48. Eisen D, Carrozzo M, Sebastian J-VB, Thongprasom K. Number V. Oral lichen planus: Clinical features and management. Oral Dis 2005: 11: 338-349.

49. Eisen D, Ellis CN, Duell EA, Griffiths CEM, Voorhees JJ. Effect of topical cyclosporine rinse on oral lichen planus: A double-blind analysis. N Engl J Med 1990: 323: 290-294.

50. Fernando MM, Stevens CR, Sabeti PC, Walsh EC, McWhinnie AJ, Shah A, Green T, Rioux JD, Vyse TJ. Identification of two independent risk factors for lupus within the MHC in United Kingdom families. PLoS Genet 2007: 3. doi:10.1371/journal.pgen.0030192

51. Filipovich AH. Diagnosis and manifestations of chronic graft-versus-host disease. Best Pract Res Clin Haematol 2008: 21: 251-257.

52. Fitzpatrick SG, Hirsch SA, Gordon SC. The malignant transformation of oral lichen planus and oral lichenoid lesions A systematic review. J Am Dent Assoc 2014: 145: 45-56.

53. Fourie J, van Heerden WF, McEachen SC, van Zyl A. Chronic ulcerative stomatitis: a distinct clinical entity? SADJ J South Afr Dent Assoc Tydskr Van Suid-Afr Tandheelkd Ver 2011: 66: 119121.

54. Frieling $\mathrm{U}$, Bonsmann $\mathrm{G}$, Schwarz $\mathrm{T}$, Luger TA, Beissert S. Treatment of severe lichen planus with mycophenolate mofetil. J Am Acad Dermatol 2003: 49: 1063-1066.

55. Fritzler MJ. Toward a new autoantibody diagnostic orthodoxy: Understanding the bad, good and indifferent. Autoimmun Highlights 2012: 3: 51-58. 
56. Fu J, Zhu X, Dan H, Zhou Y, Liu C, Wang F, Li Y, Liu N, Chen Q, Xu Y, Zeng X, Jiang L. Amlexanox is as effective as dexamethasone in topical treatment of erosive oral lichen planus: A short-term pilot study. Oral Surg Oral Med Oral Pathol Oral Radiol 2012: 113: 638-643.

57. Gandolfo S, Richiardi L, Carrozzo M, Broccoletti R, Carbone M, Pagano M, Vestita C, Rosso S, Merletti F. Risk of oral squamous cell carcinoma in 402 patients with oral lichen planus: A follow-up study in an Italian population. Oral Oncol 2004: 40: 77-83.

58. Gladman DD, Urowitz MB, Esdaile JM, Hahn BH, Klippel J, Lahita R, Liang MH, Schur P, Petri M, Wallace D. Guidelines for referral and management of systemic lupus erythematosus in adults. Arthritis Rheum 1999: 42: 1785-1796.

59. Gonzalez-Moles MA, Morales P, Rodriguez-Archilla A, Isabel IR-A, Gonzalez-Moles S. Treatment of severe chronic oral erosive lesions with clobetasol propionate in aqueous solution. Oral Surg Oral Med Oral Pathol Oral Radiol Endod 2002: 93: 264-270.

60. Gonzalez-Moles MA, Ruiz-Avila I, Rodriguez-Archilla A, Morales-Garcia P, Mesa-Aguado F, Bascones-Martinez A, Bravo M. Treatment of severe erosive gingival lesions by topical application of clobetasol propionate in custom trays. Oral Surg Oral Med Oral Pathol Oral Radiol Endod 2003: 95: 688-692.

61. Gümrü B. A retrospective study of 370 patients with oral lichen planus in Turkey. Med Oral Patol Oral Cirugia Bucal 2013: 18: e427-e432.

62. Guyot AD, Farhi D, Ingen-Housz-Oro S, Bussel A, Parquet N, Rabian C, Bachelez H, Francès $C$. Treatment of refractory erosive oral lichen planus with extracorporeal photochemotherapy: 12 Cases. Br J Dermatol 2007: 156: 553-556.

63. Hamada T, Fujimoto W, Okazaki F, Asagoe K, Arata J, Iwatsuki K. Lichen planus pemphigoides and multiple keratoacanthomas associated with colon adenocarcinoma [15]. Br J Dermatol 2004: 151: 252-254.

64. Handley TPB, Ogden GR. Dyskeratosis congenita: Oral hyperkeratosis in association with lichenoid reaction. J Oral Pathol Med 2006: 35: 508-512.

65. Harley ITW, Kaufman KM, Langefeld CD, Harley JB, Kelly JA. Genetic susceptibility to SLE: New insights from fine mapping and genome-wide association studies. Nat Rev Genet 2009: 10: 285-290.

66. Harley JB, Alarcón-Riquelme ME, Criswell LA, Jacob CO, Kimberly RP, Moser KL, Tsao BP, Vyse TJ, Langefeld CD, Nath SK, Guthridge JM, Cobb BL, Mirel DB, Marion MC, Williams AH, Divers J, Wang W, Frank SG, Namjou B, Gabriel SB, Lee AT, Gregersen PK, Behrens TW, Taylor KE, Fernando M, Zidovetzki R, Gaffney PM, Edberg JC, Rioux JD, Ojwang JO, James JA, Merrill JT, Gilkeson GS, Seldin MF, Yin H, Baechler EC, Li Q-Z, Wakeland EK, Bruner GR, Kaufman KM, Kelly JA. Genome-wide association scan in women with systemic lupus erythematosus identifies susceptibility variants in ITGAM, PXK, KIAA1542 and other loci. Nat Genet 2008: 40: 204-210.

67. Helander SD, Rogers III RS. The sensitivity and specificity of direct immunofluorescence testing in disorders of mucous membranes. J Am Acad Dermatol 1994: 30: 65-75.

68. Helou J, Allbritton J, Anhalt GJ. Accuracy of indirect immunofluorescence testing in the diagnosis of paraneoplastic pemphigus. J Am Acad Dermatol 1995: 32: 441-447. 
69. Hodgson TA, Sahni N, Kaliakatsou F, Buchanan JAG, Porter SR. Long-term efficacy and safety of topical tacrolimus in the management of ulcerative/erosive oral lichen planus. Eur J Dermatol 2003: 13: 466-470.

70. Holmstrup P, Schiøtz AW, Westergaard J. Effect of dental plaque control on gingival lichen planus. Oral Surg Oral Med Oral Pathol 1990: 69: 585-590.

71. Holmstrup P, Thorn JJ, Rindum J, Pindborg JJ. Malignant development of lichen planus-affected oral mucosa. J Oral Pathol 1988: 17: 219-225.

72. Huerta Leteurtre N, Bagan Sebastian JV, Cardona Tortajada F, Lloria de Miguel E, Jimenez Soriano Y, Basterra Alegria J. Oral lichen planus plaques and homogeneous leukoplasia: Comparative results of treatment with CO2 laser. Acta Otorrinolaringol Esp 1999: 50: 543-547.

73. Hung T, Crawford RI, Martinka M. Degree of histologic inflammation in lupus erythematosus and direct immunofluorescence results: Red and inflamed lesions do not increase the chances of getting a bright band. J Cutan Med Surg 2013: 17: 22-26.

74. Imanguli MM, Alevizos I, Brown R, Pavletic SZ, Atkinson JC. Oral graft-versus-host disease. Oral Dis 2008: 14: 396-412.

75. Islam MN, Cohen DM, Ojha J, Stewart CM, Katz J, Bhattacharyya I. Chronic ulcerative stomatitis: Diagnostic and management challenges-four new cases and review of literature. Oral Surg Oral Med Oral Pathol Oral Radiol Endodontology 2007: 104: 194-203.

76. Ismail SB, Kumar SK, Zain RB. Oral lichen planus and lichenoid reactions: etiopathogenesis, diagnosis, management and malignant transformation. J Oral Sci 2007: 49: 89-106.

77. Itin $P$, Surber $C$, Büchner $S$. Lack of effect after local treatment with a new ciclosporin formulation in recalcitrant erosive oral lichen planus. Dermatology 1992: 185: 262-265.

78. Jaremko WM, Beutner EH, Kumar V, Kipping H, Condry P, Zeid MY, Kauffman CL, Tatakis DN, Chorzelski TP. Chronic ulcerative stomatitis associated with a specific immunologic marker. $J$ Am Acad Dermatol 1990: 22: 215-220.

79. Järvinen TM, Hellquist A, Koskenmies S, Einarsdottir E, Koskinen LLE, Jeskanen L, Berglind L, Panelius J, Hasan T, Ranki A, Kere J, Saarialho-Kere U. Tyrosine kinase 2 and interferon regulatory factor 5 polymorphisms are associated with discoid and subacute cutaneous lupus erythematosus. Exp Dermatol 2010: 19: 123-131.

80. Järvinen TM, Hellquist A, Koskenmies S, Einarsdottir E, Panelius J, Hasan T, Julkunen $\mathrm{H}$, Padyukov L, Kvarnström M, Wahren-Herlenius M, Nyberg F, D'Amato M, Kere J, Saarialho-Kere $U$. Polymorphisms of the ITGAM gene confer higher risk of discoid cutaneous than of systemic lupus erythematosus. PLOS ONE 2010: 5. doi:10.1371/journal.pone.0014212

81. Jensen SJ. Maximum contents of mercury in dental silver amalgams. Scand J Dent Res 1985: 93: 84-88.

82. Jessop S, Whitelaw DA, Delamere FM. Drugs for discoid lupus erythematosus. Cochrane Database Syst Rev Published Online First: 2009. doi:10.1002/14651858.CD002954.pub2

83. Jiménez Y, Gavaldá C, Carbonell E, Margaix M, Sarrión G. Lichen sclerosus of the oral mucosa: A case report. Med Oral Patol Oral Cirugia Bucal 2008: 13: E403-E406. 
84. Jin X, Wang J, Zhu L, Wang L, Dan H, Zeng X, Chen Q. Association between -308 G/A polymorphism in TNF- $\alpha$ gene and lichen planus: A meta-analysis. J Dermatol Sci 2012: 68: 127134.

85. Jonsson R, Heyden G, Westberg NG, Nyberg G. Oral mucosal lesions in systemic lupus erythematosus - A clinical, histopathological and immunopathological study. J Rheumatol 1984: 11: 38-42.

86. Jorizzo JL, Salisbury PL, Rogers III RS, Goldsmith SM, Shar GG, Callen JP, Wise CM, Semble EL, White WL. Oral lesions in systemic lupus erythematosus: Do ulcerative lesions represent a necrotizing vasculitis? J Am Acad Dermatol 1992: 27: 389-394.

87. Kaliakatsou F, Hodgson TA, Lewsey JD, Hegarty AM, Murphy AG, Porter SR. Management of recalcitrant ulcerative oral lichen planus with topical tacrolimus. J Am Acad Dermatol 2002: 46: 35-41.

88. Katz J, Goultschin J, Benoliel R, Rotstein I, Pisanty S. Lichen planus evoked by periodontal surgery. J Clin Periodontol 1988: 15: 263-265.

89. Khudhur AS, Di Zenzo G, Carrozzo M. Oral lichenoid tissue reactions: Diagnosis and classification. Expert Rev Mol Diagn 2014: 14: 169-184.

90. Köllner K, Wimmershoff $\mathrm{M}$, Landthaler M, Hohenleutner U. Treatment of oral lichen planus with the 308-nm UVB excimer laser - Early preliminary results in eight patients. Lasers Surg Med 2003: 33: 158-160.

91. Lamey PJ, McCartan BE, MacDonald DG, MacKie RM. Basal cell cytoplasmic autoantibodies in oral lichenoid reactions. Oral Surg Oral Med Oral Pathol Oral Radiol Endod 1995: 79: 44-49.

92. Lee HY, Blazek C, Beltraminelli H, Borradori L. Oral mucous membrane pemphigoid: Complete response to topical tacrolimus. Acta Derm Venereol 2011: 91: 604-605.

93. Lee LA, Walsh P, Prater CA, Su L-J, Marchbank A, Egbert TB, Dellavalle RP, Targoff IN, Kaufman KM, Chorzelski TP, Jablonska S. Characterization of an autoantigen associated with chronic ulcerative stomatitis: The CUSP autoantigen is a member of the p53 family. J Invest Dermatol 1999: 113: 146-151.

94. Lehner T, Lyne C. Adrenal function during topical oral corticosteroid treatment. Br Med J 1969: 4: 138-141.

95. Lener EV, Brieva J, Schachter M, West LE, West DP, El-Azhary RA. Successful treatment of erosive lichen planus with topical tacrolimus. Arch Dermatol 2001: 137: 419-422.

96. Levell N, lain Macleod R, Marks J. Lack of effect of cyclosporin mouthwash in oral lichen planus. The Lancet 1991: 337: 796-797.

97. Liu AY, Valenzuela R, Helm TN, Camisa C, Melton AL, Bergfeld WF. Indirect immunofluorescence on rat bladder transitional epithelium: A test with high specificity for paraneoplastic pemphigus. J Am Acad Dermatol 1993: 28: 696-699.

98. Liu S, Yao S, Wei W, Tian W, Zhang H, Wang B. Hepatitis $\mathrm{C}$ virus and lichen planus: A reciprocal association determined by a meta-analysis. Arch Dermatol 2009: 145: 1040-1047. 
99. Liu W, Shen Z-Y, Wang L-J, Hu Y-H, Shen X-M, Zhou Z-T, Li J. Malignant potential of oral and labial chronic discoid lupus erythematosus: A clinicopathological study of 87 cases.

Histopathology 2011: 59: 292-298.

100. Lodi G, Pellicano R, Carrozzo M. Hepatitis C virus infection and lichen planus: A systematic review with meta-analysis. Oral Dis 2010: 16: 601-612.

101. Lodi G, Tarozzi M, Sardella A, Demarosi F, Canegallo L, Di Benedetto D, Carrassi A. Miconazole as adjuvant therapy for oral lichen planus: A double-blind randomized controlled trial. $\mathrm{Br} \mathrm{J}$ Dermatol 2007: 156: 1336-1341.

102. Lozada F, Silverman Jr. S, Migliorati C. Adverse side effects associated with prednisone in the treatment of patients with oral inflammatory ulcerative diseases. J Am Dent Assoc 1984: 109: 269-270.

103. Lozada-Nur F, Miranda C, Maliksi R. Double-blind clinical trial of $0.05 \%$ clobetasol proprionate ointment in orabase and $0.05 \%$ fluocinonide ointment in orabase in the treatment of patients with oral vesiculoerosive diseases. Oral Surg Oral Med Oral Pathol 1994: 77: 598-604.

104. Mansourian A, Momen-Heravi F, Saheb-Jamee M, Esfehani M, Khalilzadeh O, Momen-Beitollahi J. Comparison of aloe vera mouthwash with triamcinolone acetonide $0.1 \%$ on oral lichen planus: A randomized double-blinded clinical trial. Am J Med Sci 2011: 342: 447-451.

105. Maoz KB, Brenner S. Lichen planus pemphigoides triggered by narrowband UVB, paracetamol, and ibuprofen, with autoantibodies to 130kDa antigen. Skinmed 2008: 7: 33-36.

106. Mattsson U, Magnusson B, Jontell M. Squamous cell carcinoma in a patient with oral lichen planus treated with topical application of tacrolimus. Oral Surg Oral Med Oral Pathol Oral Radiol Endodontology 2010: 110: e19-e25.

107. Max Robinson C, Oxley JD, Weir J, Eveson JW. Lichenoid and granulomatous stomatitis: An entity or a non-specific inflammatory process? J Oral Pathol Med 2006: 35: 262-267.

108. McCartan BE, Lamey P. Lichen planus--specific antigen in oral lichen planus and oral lichenoid drug eruptions. Oral Surg Oral Med Oral Pathol Oral Radiol Endod 2000: 89: 585-587.

109. McCartan BE, McCreary CE. Oral lichenoid drug eruptions. Oral Dis 1997: 3: 58-63.

110. McCaughey C, MacHan M, Bennett R, Zone JJ, Hull CM. Pimecrolimus $1 \%$ cream for oral erosive lichen planus: A 6-week randomized, double-blind, vehicle-controlled study with a 6-week open-label extension to assess efficacy and safety. J Eur Acad Dermatol Venereol 2011: 25: 1061-1067.

111. McCauliffe DP. Cutaneous lupus erythematosus. Semin Cutan Med Surg 2001: 20: 14-26.

112. McParland $\mathrm{H}$, Warnakulasuriya $\mathrm{S}$. Oral Lichenoid contact lesions to mercury and dental Amalgam- A review. J Biomed Biotechnol 2012: 2012. doi:10.1155/2012/589569

113. Merola JF, Prystowsky SD, Iversen C, Gomez-Puerta JA, Norton T, Tsao P, Massarotti E, Schur P, Bermas $\mathrm{B}$, Costenbader $\mathrm{KH}$. Association of discoid lupus erythematosus with other clinical manifestations among patients with systemic lupus erythematosus. J Am Acad Dermatol 2013: 69: 19-24. 
114. Mignogna MD, Fortuna G, Leuci S, Stasio L, Mezza E, Ruoppo E. Lichen planus pemphigoides, a possible example of epitope spreading. Oral Surg Oral Med Oral Pathol Oral Radiol Endodontology 2010: 109: 837-843.

115. Morrison L, Kratochvil III FJ, Gorman A. An open trial of topical tacrolimus for erosive oral lichen planus. J Am Acad Dermatol 2002: 47: 617-620.

116. Muzio LL, Della Valle A, Mignogna MD, Pannone G, Bucci P, Bucci E, Sciubba J. The treatment of oral aphthous ulceration or erosive lichen planus with topical clobetasol propionate in three preparations: A clinical and pilot study on 54 patients. J Oral Pathol Med 2001: 30: 611-617.

117. Nagao K, Chen K-R. A case of lupus erythematosus/lichen planus overlap syndrome. J Dermatol 2006: 33: 187-190.

118. Namjou B, Kothari PH, Kelly JA, Glenn SB, Ojwang JO, Adler A, Alarcón-Riquelme ME, Gallant CJ, Boackle SA, Criswell LA, Kimberly RP, Brown E, Edberg J, Stevens AM, Jacob CO, Tsao BP, Gilkeson GS, Kamen DL, Merrill JT, Petri M, Goldman RR, Vila LM, Anaya J-M, Niewold TB, Martin J, Pons-Estel BA, Sabio JM, Callejas JL, Vyse TJ, Bae S-C, Perrino FW, Freedman BI, Scofield RH, Moser KL, Gaffney PM, James JA, Langefeld CD, Kaufman KM, Harley JB, Atkinson JP. Evaluation of the TREX1 gene in a large multi-ancestral lupus cohort. Genes Immun 2011: 12: 270-279.

119. Nguyen VT, Ndoye A, Bassler KD, Shultz LD, Shields MC, Ruben BS, Webber RJ, Pittelkow MR, Lynch PJ, Grando SA. Classification, clinical manifestations, and immunopathological mechanisms of the epithelial variant of paraneoplastic autoimmune multiorgan syndrome: A reappraisal of paraneoplastic pemphigus. Arch Dermatol 2001: 137: 193-206.

120. Nico MMS, Vilela MAC, Rivitti EA, Lourenço SV. Oral lesions in lupus erythematosus: Correlation with cutaneous lesions. Eur J Dermatol 2008: 18: 376-381.

121. Nieboer $\mathrm{C}$. The reliability of immunofluorescence and histopathology in the diagnosis of discoid lupus erythematosus and lichen planus. Br J Dermatol 1987: 116: 189-198.

122. Nikolskaia OV, Nousari CH, Anhalt GJ. Paraneoplastic pemphigus in association with Castleman's disease. Br J Dermatol 2003: 149: 1143-1151.

123. Noël B. Lupus erythematosus and other autoimmune diseases related to statin therapy: A systematic review. J Eur Acad Dermatol Venereol 2007: 21: 17-24.

124. Nyfeler B, Pichler WJ. The lymphocyte transformation test for the diagnosis of drug allergy: Sensitivity and specificity. Clin Exp Allergy 1997: 27: 175-181.

125. Oke V, Wahren-Herlenius M. Cutaneous lupus erythematosus: Clinical aspects and molecular pathogenesis. J Intern Med 2013: 273: 544-554.

126. Olivier V, Lacour J-P, Mousnier A, Garraffo R, Monteil RA, Ortonne J-P. Treatment of chronic erosive oral lichen planus with low concentrations of topical tacrolimus: An open prospective study. Arch Dermatol 2002: 138: 1335-1338.

127. Parodi A, Cozzani E, Chorzelski TP, Beutner EH, Rebora A. A molecule of about $70 \mathrm{kd}$ is the immunologic marker of chronic ulcerative stomatitis. J Am Acad Dermatol 1998: 38: 10051006. 
128. Parodi A, Cozzani E, Massone C, Rebora A, Priano L, Ghigliotti G, Balbi P, Rongioletti F, Micalizzi C, Cestari R, Varaldo G, Barabino G, Cannata G, Drago F, Moreno V, Schiazza L, Muzio G, Scaparro E, Alibrandi B, Bandelloni R, Ciaccio M, Desirello G, Isola PM, Ottoboni S, Rampini P, Santoro G, Sorbara S, Virno G. Prevalence of stratified epithelium-specific antinuclear antibodies in 138 patients with lichen planus. J Am Acad Dermatol 2007: 56: 974-978.

129. Passeron T, Lacour J-P, Fontas E, Ortonne J-P. Treatment of oral erosive lichen planus with $1 \%$ pimecrolimus cream: A double-blind, randomized, prospective trial with measurement of pimecrolimus levels in the blood. Arch Dermatol 2007: 143: 472-476.

130. Pemberton MN, Yar R, Sloan P. Fixed drug eruption to oxybutynin. Oral Surg Oral Med Oral Pathol Oral Radiol Endodontology 2008: 106: e19-e21.

131. Petruzzi M, De Benedittis M, Grassi R, Cassano N, Vena G, Serpico R. Oral lichen planus: A preliminary clinical study on treatment with tazarotene. Oral Dis 2002: 8: 291-295.

132. Petti S, Rabiei M, De Luca M, Scully C. The magnitude of the association between hepatitis C virus infection and oral lichen planus: meta-analysis and case control study.

2011.http://www.scopus.com/inward/record.url?eid=2-s2.0-

79955122439\&partnerID=40\&md5=fb2e66580e950d11a99926a60aa72ba0

133. Pilli M, Penna A, Zerbini A, Vescovi P, Manfredi M, Negro F, Carrozzo M, Mori C, Giuberti T, Ferrari C, Missale G. Oral lichen planus pathogenesis: A role for the HCV-specific cellular immune response. Hepatology 2002: 36: 1446-1452.

134. Poot AM, Diercks GFH, Kramer D, Schepens I, Klunder G, Hashimoto T, Borradori L, Jonkman MF, Pas HH. Laboratory diagnosis of paraneoplastic pemphigus. Br J Dermatol 2013: 169: 1016-1024.

135. Probst C, Schlumberger W, Stöcker W, Recke A, Schmidt E, Hashimoto T, Zhu XJ, Zillikens D, Komorowski L. Development of ELISA for the specific determination of autoantibodies against envoplakin and periplakin in paraneoplastic pemphigus. Clin Chim Acta 2009: 410: 13-18.

136. Rebora A, Parodi A, Murialdo G. Basiliximab is effective for erosive lichen planus [4]. Arch Dermatol 2002: 138: 1100-1101.

137. Reddy RL, Reddy RS, Ramesh T, Singh TR, Swapna LA, Laxmi NV. Randomized trial of aloe vera gel vs triamcinolone acetonide ointment in the treatment of oral lichen planus. Quintessence Int Berl Ger 1985 2012: 43: 793-800.

138. Rinaggio J, Crossland DM, Zeid MY. A determination of the range of oral conditions submitted for microscopic and direct immunofluorescence analysis. J Periodontol 2007: 78: 1904-1910.

139. Rödström P-O, Hakeberg M, Jontell M, Nordin P. Erosive oral lichen planus treated with clobetasol propionate and triamcinolone acetonide in orabase: A double-blind clinical trial. $J$ Dermatol Treat 1994: 5: 7-10.

140. Rödström P-O, Jontell M, Mattsson U, Holmberg E. Cancer and oral lichen planus in a Swedish population. Oral Oncol 2004: 40: 131-138.

141. Rothfield N, Sontheimer RD, Bernstein M. Lupus erythematosus: systemic and cutaneous manifestations. Clin Dermatol 2006: 24: 348-362. 
142. Rozycki TW, Rogers III RS, Pittelkow MR, McEvoy MT, El-Azhary RA, Bruce AJ, Fiore JP, Davis MDP. Topical tacrolimus in the treatment of symptomatic oral lichen planus: A series of 13 patients. J Am Acad Dermatol 2002: 46: 27-34.

143. Salazar-Sánchez N, López-Jornet P, Camacho-Alonso F, Sánchez-Siles M. Efficacy of topical Aloe vera in patients with oral lichen planus: A randomized double-blind study. J Oral Pathol Med 2010: 39: 735-740.

144. Sapadin AN, Phelps RG, Fellner MJ, Kantor I. Lichen planus pemphigoides presenting with a strikingly unilateral distribution. Int J Dermatol 1998: 37: 942-946.

145. Scardina GA, Messina P, Carini F, Maresi E. A randomized trial assessing the effectiveness of different concentrations of isotretinoin in the management of lichen planus. Int J Oral Maxillofac Surg 2006: 35: 67-71.

146. Schepens I, Jaunin F, Begre N, Läderach U, Marcus K, Hashimoto T, Favre B, Borradori L. The protease inhibitor alpha-2-macroglobuline-like-1 is the p170 antigen recognized by paraneoplastic pemphigus autoantibodies in human. PLOS ONE 2010: 5. doi:10.1371/journal.pone.0012250

147. Scully C, Carrozzo M. Oral mucosal disease: Lichen planus. Br J Oral Maxillofac Surg 2008: 46: 15-21.

148. Scully C, Eisen D, Carrozzo M. Management of oral lichen planus. Am J Clin Dermatol 2000: 1: 287-306.

149. Seno K, Ohno J, Ota N, Hirofuji T, Taniguchi K. Lupus-like oral mucosal lesions in mercuryinduced autoimmune response in Brown Norway rats. BMC Immunol 2013: 14.

doi:10.1186/1471-2172-14-47

150. Siegfried EC, Jaworski JC, Hebert AA. Topical calcineurin inhibitors and lymphoma risk: Evidence update with implications for daily practice. Am J Clin Dermatol 2013: 14: 163-178.

151. Sieg P, Von Domarus H, Von Zitzewitz V, Iven H, Farber L. Topical cyclosporin in oral lichen planus: A controlled, randomized, prospective trial. Br J Dermatol 1995: 132: 790-794.

152. Solomon LW. Chronic ulcerative stomatitis. Oral Dis 2008: 14: 383-389.

153. Solomon LW, Aguirre A, Neiders M, Costales-Spindler A, Jividen Jr. GJ, Zwick MG, Kumar V. Chronic ulcerative stomatitis: Clinical, histopathologic, and immunopathologic findings. Oral Surg Oral Med Oral Pathol Oral Radiol Endod 2003: 96: 718-726.

154. Solomon LW, Helm TN, Stevens C, Neiders ME, Kumar V. Clinical and immunopathologic findings in oral lichen planus pemphigoides. Oral Surg Oral Med Oral Pathol Oral Radiol Endodontology 2007: 103: 808-813.

155. Solomon LW, Stark PC, Winter L, Kumar V, Sinha S. ELISA test for p63 antibodies in chronic ulcerative stomatitis. Oral Dis 2010: 16: 151-155.

156. Sontheimer RD. Lichenoid tissue reaction/interface dermatitis: Clinical and histological perspectives. J Invest Dermatol 2009: 129: 1088-1099. 
157. Soria A, Agbo-Godeau S, Taïeb A, Francès C. Treatment of refractory oral erosive lichen planus with topical rapamycin: 7 Cases. Dermatology 2008: 218: 22-25.

158. Stoebner P-E, Michot C, Ligeron C, Durand L, Meynadier J, Meunier L. Simvastatin-induced lichen planus pemphigoides. Ann Dermatol Venereol 2003: 130: 187-190.

159. Swift JC, Rees TD, Plemons JM, Hallmon WW, Wright JC. The effectiveness of $1 \%$ pimecrolimus cream in the treatment of oral erosive lichen planus. J Periodontol 2005: 76: 627-635.

160. Tamada Y, Yokochi K, Nitta Y, Ikeya T, Hara K, Owaribe K. Lichen planus pemphigoides: Identification of $180 \mathrm{kd}$ hemidesmosome antigen. J Am Acad Dermatol 1995: 32: 883-887.

161. Tan E., Cohen AS, Fries J., Masi AT, Mcshane DJ, Rothfield N., Schaller J., Talal N, Winchester RJ. The 1982 revised criteria for the classification of systemic lupus erythrematosus. Arthritis Rheum 1982: 25: 1271-1277.

162. Tennis P, Gelfand JM, Rothman KJ. Evaluation of cancer risk related to atopic dermatitis and use of topical calcineurin inhibitors. Br J Dermatol 2011: 165: 465-473.

163. Thompson DF, Skaehill PA. Drug-induced lichen planus. Pharmacotherapy 1994: 14: 561-571.

164. Thongprasom K, Carrozzo M, Furness S, Lodi G. Interventions for treating oral lichen planus. Cochrane Database Syst Rev Online Published Online First: 2011.http://www.scopus.com/inward/record.url?eid=2-s2.079960987466\&partnerID $=40 \& m d 5=d a e 25 d 59777 d b 12$ caf5cec34963f1120

165. Thongprasom K, Luengvisut $P$, Wongwatanakij $A$, Boonjatturus $C$. Clinical evaluation in treatment of oral lichen planus with topical fluocinolone acetonide: A 2-year follow-up. J Oral Pathol Med 2003: 32: 315-322.

166. Thorne JE, Jabs DA, Nikolskaia O, Anhalt G, Nousari HC. Discoid lupus erythematosus and cicatrizing conjunctivitis: Clinicopathologic study of two cases. Ocul Immunol Inflamm 2002: 10: 287-292.

167. Thornhill MH, Pemberton MN, Simmons RK, Theaker ED. Amalgam-contact hypersensitivity lesions and oral lichen planus. Oral Surg Oral Med Oral Pathol Oral Radiol Endod 2003: 95: 291-299.

168. Togliatto M, Carrozzo M, Conrotto D, Pagano M, Gandolfo S. Oral lupus erythematosus. Description and analysis of 11 cases. Minerva Stomatol 2000: 49: 35-40.

169. Torti DC, Jorizzo JL, McCarty MA. Oral lichen planus: A case series with emphasis on therapy. Arch Dermatol 2007: 143: 511-515.

170. Tradati N, Chiesa F, Rossi N, Grigolato R, Formelli F, Costa A, de Palo G. Successful topical treatment of oral lichen planus and leukoplakias with fenretinide (4-HPR). Cancer Lett 1994: 76: 109-111.

171. Trehan M, Taylor CR. Low-Dose Excimer 308-nm Laser for the Treatment of Oral Lichen Planus. Arch Dermatol 2004: 140: 415-420.

172. Uva L, Miguel D, Pinheiro C, Freitas JP, Marques Gomes M, Filipe P. Cutaneous manifestations of systemic lupus erythematosus. Autoimmune Dis 2012: 1. doi:10.1155/2012/834291 
173. Van der Meij EH, Van der Waal I. Lack of clinicopathologic correlation in the diagnosis of oral lichen planus based on the presently available diagnostic criteria and suggestions for modifications. J Oral Pathol Med 2003: 32: 507-512.

174. Van Der Waal I. Oral lichen planus and oral lichenoid lesions; a critical appraisal with emphasis on the diagnostic aspects. Med Oral Patol Oral Cirugia Bucal 2009: 14: E310-E314.

175. Vassileva S. Drug-induced pemphigoid: Bullous and cicatricial. Clin Dermatol 1998: 16: 379387.

176. Volz T, Caroli U, Lüdtke H, Bräutigam M, Kohler-Späth H, Röcken M, Biedermann T. Pimecrolimus cream $1 \%$ in erosive oral lichen planus - A prospective randomized double-blind vehicle-controlled study. Br J Dermatol 2008: 159: 936-941.

177. Voûte ABE, Schulten EAJM, Langendijk PNJ, Kostense PJ, van der Waal I. Fluocinonide in an adhesive base for treatment of oral lichen planus. A double-blind, placebo-controlled clinical study. Oral Surg Oral Med Oral Pathol 1993: 75: 181-185.

178. Voûte ABE, Schulten EAJM, Langendijk PNJ, Nieboer C, van der Waal I. Cyclosporin A in an adhesive base for treatment of recalcitrant oral lichen planus. An open trial. Oral Surg Oral Med Oral Pathol 1994: 78: 437-441.

179. Walling $\mathrm{H}$, Sontheimer R. Cutaneous lupus erythematosus: Issues in diagnosis and treatment. Am J Clin Dermatol 2009: 10: 365-381.

180. Washio K, Nakamura A, Fukuda S, Hashimoto T, Horikawa T. A case of lichen planus pemphigoides successfully treated with a combination of cyclosporine a and prednisolone. Case Rep Dermatol 2013: 5: 84-87.

181. Werth VP. Clinical manifestations of cutaneous lupus erythematosus. Autoimmun Rev 2005: 4: 296-302.

182. Woo S-B, Lee SJ, Schubert MM. Graft-vs.-host disease. Crit Rev Oral Biol Med 1997: 8: 201-216.

183. Wörle B, Wollenberg A, Schaller M, Kunzelmann K-H, Plewig G, Meurer M. Chronic ulcerative stomatitis. Br J Dermatol 1997: 137: 262-265.

184. Wu Y, Zhou G, Zeng H, Xiong C-R, Lin M, Zhou H-M. A randomized double-blind, positivecontrol trial of topical thalidomide in erosive oral lichen planus. Oral Surg Oral Med Oral Pathol Oral Radiol Endodontology 2010: 110: 188-195.

185. Yamauchi M, Moriyama M, Hayashida JN, Maehara T, Ishiguro N, Kubota K, Furukawa S, Ohta M, Sakamoto M, Tanaka A, Nakamura S. Myeloid dendritic cells stimulated by thymic stromal lymphopoietin promote Th2 immune responses and the pathogenesis of oral lichen planus. PLoS One 2017: 12: e0173017.

186. Yarom N. Etanercept for the management of oral lichen planus. Am J Clin Dermatol 2007: 8: 121.

187. Yoon KH, Kim SC, Kang DS, Lee IJ. Lichen planus pemphigoides with circulating autoantibodies against 200 and 180 kDa epidermal antigens. Eur J Dermatol 2000: 10: 212-214. 
188. Yuan A, Woo S-B. Adverse drug events in the oral cavity. Oral Surg Oral Med Oral Pathol Oral Radiol 2015: 119: 35-47.

189. Zaraa I, Mahfoudh A, Sellami MK, Chelly I, El Euch D, Zitouna M, Mokni M, Makni S, Osman AB. Lichen planus pemphigoides: Four new cases and a review of the literature. Int I Dermatol 2013: 52: 406-412.

190. Zillikens D, Caux F, Mascaro Jr. JM, Wesselmann U, Schmidt E, Prost C, Callen JP, Bröcker E-B, Diaz LA, Giudice GJ. Autoantibodies in lichen planus pemphigoides react with a novel epitope within the C-terminal NC16A domain of BP180. J Invest Dermatol 1999: 113: 117-121. 